\title{
Flexible Stamp for Nanoimprint Lithography
}

Nielsen, Theodor; Pedersen, Rasmus H.; Hansen, Ole; Haatainen, T.; Tollki, A.; Ahopelto, J.; Kristensen, Anders

Published in:

Technical Digest of the 18th IEEE Conference on Micro Electro Mechanical Systems, MEMS 2005

Link to article, DOI:

10.1109/MEMSYS.2005.1453978

Publication date:

2005

Document Version

Publisher's PDF, also known as Version of record

Link back to DTU Orbit

Citation $(A P A)$ :

Nielsen, T., Pedersen, R. H., Hansen, O., Haatainen, T., Tollki, A., Ahopelto, J., \& Kristensen, A. (2005). Flexible Stamp for Nanoimprint Lithography. In Technical Digest of the 18th IEEE Conference on Micro Electro

Mechanical Systems, MEMS 2005 (pp. 508-511). IEEE. https://doi.org/10.1109/MEMSYS.2005.1453978

\section{General rights}

Copyright and moral rights for the publications made accessible in the public portal are retained by the authors and/or other copyright owners and it is a condition of accessing publications that users recognise and abide by the legal requirements associated with these rights.

- Users may download and print one copy of any publication from the public portal for the purpose of private study or research.

- You may not further distribute the material or use it for any profit-making activity or commercial gain

- You may freely distribute the URL identifying the publication in the public portal 


\section{FLEXIBLE STAMP FOR NANOIMPRINT LITHOGRAPHY}

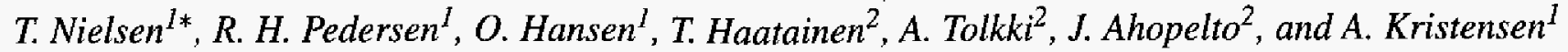 \\ ${ }^{1}$ MiC - Department of Micro and Nanotechnology, Technical University of Denmark (DTU), DK-2800 Kongens Lyngby, Denmark ${ }^{2}$ VTT Technical Research Centre of Finland, P.O. Box 1208, FIN 02044 VTT, Finland}

\begin{abstract}
The design, fabrication and performance of a flexible silicon stamp for homogenous large area nanoimprint lithography (NIL) are presented. The flexible stamp is fabricated by bulk semiconductor micro machining of a 4-inch silicon wafer and consists of thick anchor-like imprint areas connected by membranes. The bending stiffness difference between the imprint areas and the membranes ensures that the deformation of the stamp during the imprint process mainly takes place in the membranes, leaving the imprint structures unaffected. By this design the strong demand to the para! lelism between stamp and substrate in the imprint situation is decoupled from the pressing tool and the wafer quality. The stamp consist of 1562 imprint areas $(1 \mathrm{~mm} \times 1 \mathrm{~mm}$ ) containing the patterns to be replicated. The imprinted patterns are characterized with respect to the imprint depth and the polymer residual layer thickness. It is found that within a $50 \mathrm{~mm}$ diameter the polymer residual layer thickness is $18.8 \mathrm{~nm}$ with a standard deviation of $6.6 \mathrm{~nm}$.
\end{abstract}

\section{INTRODUCTION}

Nanoimprint lithography (NIL) is a parallel process lithography technique capable of replicating $\mathrm{nm}$ to $\mathrm{mm}$ sized structures in a single parallel process step [1]. In thermal NL a hard stamp, patterned with the structure to be replicated, is pressed into a thermoplast at a temperature above the glass transition temperature, $T_{g}$, of the thermoplast. When the stamp is completely pressed into the thermoplast, cooling is initiated, and the stamp is separated from the thermoplast at a temperature below $T_{g}$. Thereby the inverse stamp profile is replicated into the thermoplast, Fig. 1.

Parallel processing lithography techniques capable of patterning nm sized structures is of great interest for the volume manufacture of components containing $\mathrm{nm}$ sized features. The patterning of $\mathrm{nm}$ sized structures depend on expensive lithography techniques, e.g. electron beam lithography, $x$-ray lithography, and extreme ultra violet lithography. NIL is an obvious candidate for patterning of such structures, since only a master stamp has to be fabricated. The master stamp can then be replicated to stamp copies and these are used in the fabrication line [2]. In this way the cost of making components containing nm sized structures is reduced dramatically. The great potential of NIL to be a low cost litho-

\footnotetext{
"Corresponding author: tni@mic.dtu.dk
}

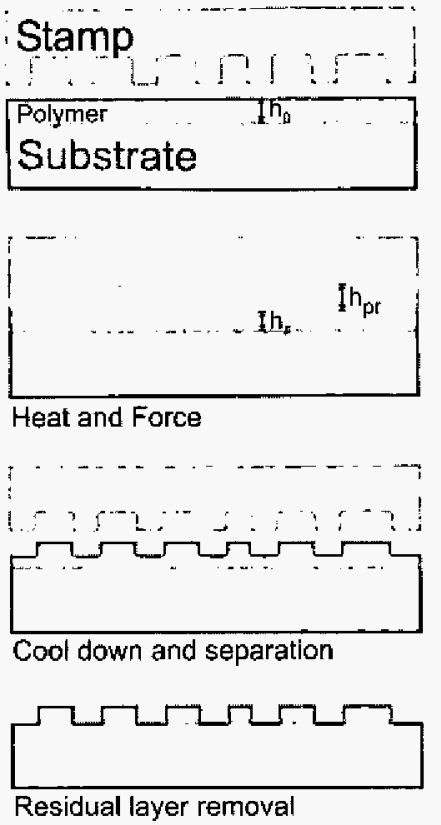

Figure 1: Overview of the nanoimprint lithography process. A patterned stamp is pressed into a thin film of thermoplast located on a hard substrate at a temperature above $T_{g}$. When the stamp is completely imprinted, cooling is initiated and at a temperature below $T_{g}$ the force is released and the stamp and substrate are separated. Finally, the polymer residual layer can be removed by e.g. an oxygen plasma etch.

graphy tool for sub- $\mu \mathrm{m}$ patterns is envisaged by the recent uptake of NIL on the International Technology Roadmap for Semiconductors (ITRS) [3], where NIL is appointed to be one of the potential lithography techniques to deliver the $32-\mathrm{nm}$ node in 2013. However, in order to fulfill the demands from the ITRS to NIL there are some challenges to solve. The most important of these are: Homogeneous large area imprint, sub$\mu \mathrm{m}$ to sub- $\mu \mathrm{m}$ aligning, error detection, fast imprint cycles and critical dimension control. The flexible silicon stamp presented here addresses the first of these challenges.

\section{DESIGN}

Considering large area thermal NIL a critical parameter is the thickness and variations of the polymer residual layer, i.e. the polymer film in the areas where the stamp protrusions have imprinted. Thick residual layers will cause pattern widen- 
ing during removal, which is needed to get access to the substrate. Variations in the residual layer will cause an uneven patterning widening, i.e. loss of the critical dimensions during removal. The removal of the residual layer is often performed by oxygen plasma etching, see Fig. 1. Knowledge about the protrusion height, $h_{\mathrm{pr}}$, the polymer thickness, $h_{0}$, and the variation of these $\delta h_{\mathrm{pr}}$ and $\delta h_{0}$ is important. In a perfect stamp filling situation where stamp and substrate are parallel and without stamp bending, mass conservation of the polymer gives the expected polymer residual layer $h_{r}$ :

$$
h_{r}=h_{0} \quad h_{\mathrm{pr}}\left(\begin{array}{ll}
1 & 0
\end{array}\right) \text {, }
$$

where $v$ is the stamp protrusion coverage, i.e. the ratio between elevated and recessed area in the imprint areas. From Eq. 1 the expected variation of the polymer residual layer, $\delta h_{r}$ is found to

$$
\delta h_{r}=\sqrt{\delta h_{0}^{2}+\left[\left(\begin{array}{ll}
\mathbf{u} & 1
\end{array}\right) \delta h_{\mathrm{pr}}\right]^{2}}
$$

Thereby it is important to control $\delta h_{0}$ and $\delta h_{\mathrm{pr}}$ in order to achieve control of the polymer residual layer thickness. In addition to this the parallelism between the stamp and substrate is important. Taking the demand to the uniformity of the residual layer to be $5 \mathrm{~nm}$ variation over a 4-inch wafer, the challenge scales up to pressing two soccer fields together in a parallel manner with an accuracy of $5 \mu \mathrm{m}$. This is a tremendous task considering that the warp of a standard 4-inch wafer is approximately $5 \mu \mathrm{m}$. An obvious way to approach the challenge of parallelism is to consider micro electro mechanical systems (MEMS) technology and exploit the possibilities of control on the $\mu \mathrm{m}$ and $\mathrm{nm}$ scale that semiconductor processing offers. By using MEMS technology in the design of the stamp the demands to the parallelism between the stamp and substrate can be removed from the imprint tool and the wafer quality and into the stamp. In fact, no matter how parallel the pressing mechanism is in an imprint tool, the wafer warp and thickness variation still has to be considered. Using a structured silicon wafer as stamp and another silicon wafer as substrate the deformation of the wafers in order to achieve contact over the whole area is not controlled. Thereby there will be an uncontrolled pattern distortion of the imprinted pattern compared to the stamp which again results in loss of the critical dimensions. The flexible stamp presented here is designed to deform outside patterned areas and the patterns will be replicated without distortion.

The principle of the flexible stamp is to have imprint areas which are weakly coupled, ideally decoupled, from each other in the direction perpendicular to the wafer plane, but fixed in the wafer plane. This will cause the individual imprint areas to be able to adopt to any curvature of the substrate, and any defects from imprinting, e.g. particle contamination, will be localized to one or a few imprint areas, see Fig 2. The fixation of the imprint areas in the wafer plane will prevent them from edging and ensure that they are imprinted parallel to the substrate.
Wafer stamp
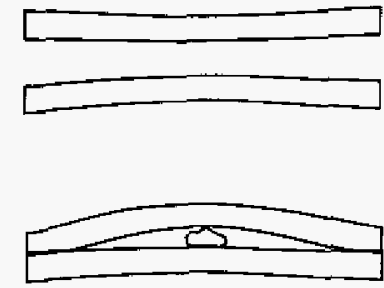

Flexible stamp
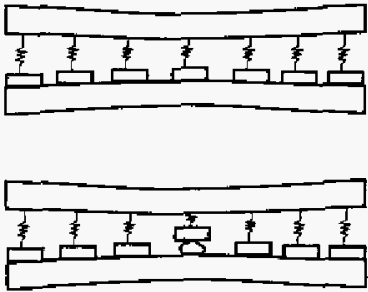

Figure 2: Hllustration of the coupling between the imprint areas. By having imprint areas that are decoupled in a direction perpendicular to the wafer plane and fixed in the plane of the wafer the flexible stamp will inherently imprint the imprint areas parallel to the substrate. Top: The warp of the stamp and substrate for a wafer stamp and a flexible stamp is illustrated. The uncontrolled deformation of the wafer stamp will cause pattern distortion, while the deformation in the case of the flexible stamp is located in areas without patterns. Bottom: The area affected by the presence of a defect between the stamp and substrate is uncontrolled in the case of the wafer stamp, but limited to one or a few imprint areas in the case of the flexible stamp.

This design principle described above is achieved by having many imprint areas which are placed on a membrane. The single imprint area consist of a mesa which is raised above the surface of the membrane, and is anchored through the membrane, Fig. 4E. The anchor has a thickness of the original silicon wafer, and the ratio between the thickness of the anchor and the thickness of the connecting membrane is 3.7 , causing the bending stiffness of the imprint areas to be approximately 50 times larger than that of the membrane. The entire back side of the flexible stamp with the anchors are embedded in a mattress of poly-dimethylsiloxane (PDMS) to be able to apply a homogeneous pressure to the stamp. The silicon membrane and the back side PDMS mattress acts as a coupled spring system, with two springs in parallel. If the membrane is assumed to be a double clamped-clamped beam and the Young's modulus of silicon and PDMS to be $170 \mathrm{GPa}$ and $750 \mathrm{kPa}$, respectively, the resulting spring constant for each imprint area is calculated to $1.85 \cdot 10^{7} \mathrm{~N} / \mathrm{m}$.

In this demonstration of the flexible stamp, 1562 imprint areas are placed within a diameter of $70 \mathrm{~mm}$ on a 4-inch silicon wafer, and the supporting PDMS mattress has a diameter of $80 \mathrm{~mm}$, see Fig. 3. All the imprint areas are $1 \mathrm{~mm} \times$ $1 \mathrm{~mm}$ and separated $0.5 \mathrm{~mm}$. The imprint areas contain identical patterns, consisting of 8 lines (numbered 1 to 8 ), being $1 \mathrm{~mm}$ long and $25 \mu \mathrm{m}$ wide. The stamp protrusion height, $h_{\mathrm{pr}}$ is $283.0 \mathrm{~nm}$ with a standard deviation of $1.9 \mathrm{~nm}$ across the wafer. The lines are separated by $100 \mu \mathrm{m}$ from each other, and the outer ones are placed $50 \mu \mathrm{m}$ from the edge of the imprint area. The protrusion coverage in each imprint area is 


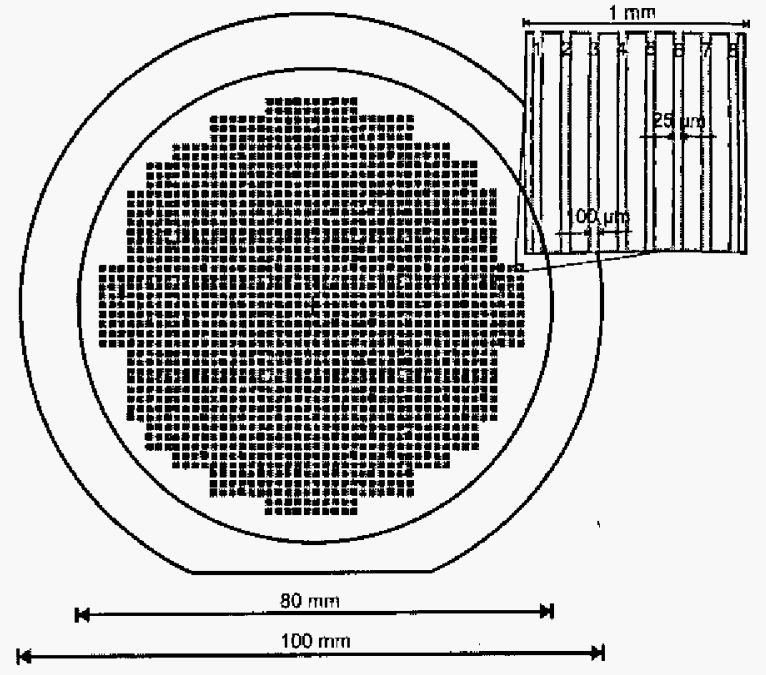

Figure 3: Overview of the imprint areas and the pattern within the areas. The 8 lines in 195 (dark) of the 1562 imprint areas have been characterized with respect to the polymer residual layer thickness. The support of the PDMS mattress on the back side has a diameter of $80 \mathrm{~mm}$.

thereby 0.2 . The reason for imprinting $\mu \mathrm{m}$-sized patterns is twofold. First, the imprint process of large structures is challenging due to the large volume of polymer moved. Secondly, the $25 \mu \mathrm{m}$ wide imprinted trenches allow for characterization of the polymer residual layer thickness.

\section{Fabrication}

The flexible stamp is fabricated from a single side polished 4-inch silicon wafer. The fabrication process is outlined in Fig. 4. A $283 \mathrm{~nm}$ thick film of silicon dioxide is thermally grown on both sides of the wafer. The oxide is removed from the back side by BHF etch (Fig. $4 \mathrm{~A}$ ). $1.5 \mu \mathrm{m}$ thick photoresist (AZ5214e, Shipley) is spin-coated onto the back side and exposed (I-line UV-lithography) in a negative process to define the imprint areas and developed (AZ351B, Shipley). 300 $\mathrm{nm}$ of aluminium is e-beam evaporated on the back side (Alcatel SCM600) and a lift-off is performed using acetone and ultrasonic agitation. The aluminium on the back side is used as a hard etch mask in a deep reactive ion etch (STS ASE) [4] which defines the membranes (Fig. 4 B). The wafer is then treated with hexamethyldisiloxane (HMDS) in a process dedicated oven and the front side is spin-coated with $1.5 \mu \mathrm{m}$ photoresist (AZ351B, Shipley). The photoresist is exposed through a mask containing the stamp protrusions. The pattern is transferred into the silicon dioxide by $\mathrm{BHF}$, using the silicon as an etch stop layer (Fig. $4 \mathrm{C}$ ). The photoresist is stripped in acetone and another $1.5 \mu \mathrm{m}$ photoresist is spincoated on top of the stamp protrusions. The mesas defining

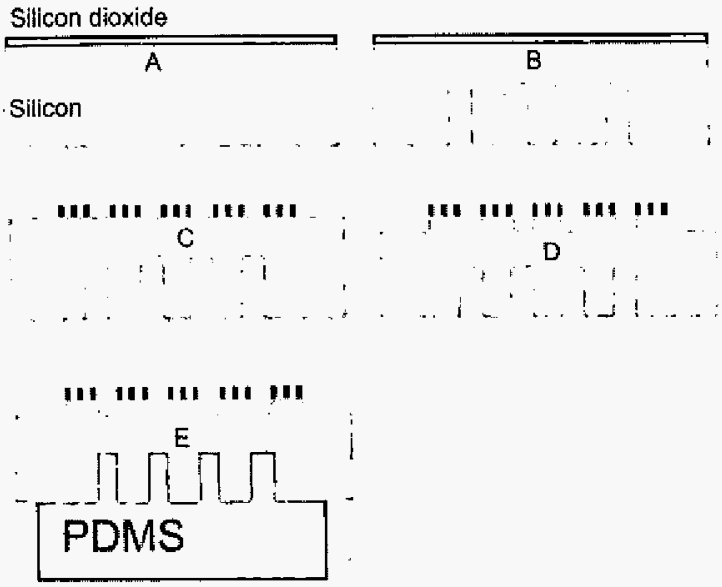

Figure 4: Fabrication sequence for the flexible silicon stamp. The final flexible stamp is a hybrid between silicon and PDMS. All the silicon processing is performed by bulk silicon micro machining which is followed by molding of the PDMS mattress to the back side.

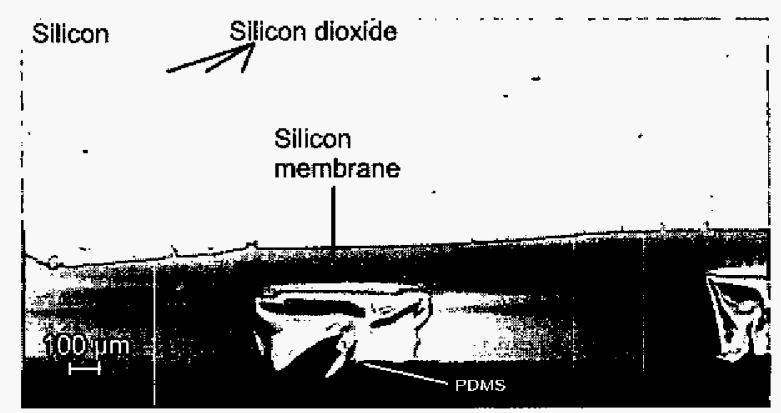

Figure 5: Scanning electron micrograph of the cross-section of the completed flexible stamp.

the imprint areas are now patterned in the photoresist by UVlithography. The photoresist serves as an etch mask in a reactive ion etch (RIE) (STS Cluster) which etches $1.7 \mu \mathrm{m}$ into the silicon (Fig. 4 D). The photoresist is stripped and an antisticking film is deposited from a $\mathrm{C}_{4} \mathrm{~F}_{8}$ plasma using the ASE [5]. Finally, the stamp is inserted into a mold for the PDMS mattress. The PDMS (Sylgard 184) is poured over the back side of the wafer and cured at $80^{\circ} \mathrm{C}$ for 2 hours in an oven (Fig. $4 \mathrm{E}$ ). A cross-sectional scanning electron micrograph of the completed flexible stamp is shown in Fig. 5.

\section{Results}

The flexible stamp is imprinted into a film of 50k poly-methylmethacrylate (PMMA) placed on a silicon substrate. The thickness of the PMMA film is $307 \mathrm{~nm}$ with a standard de- 


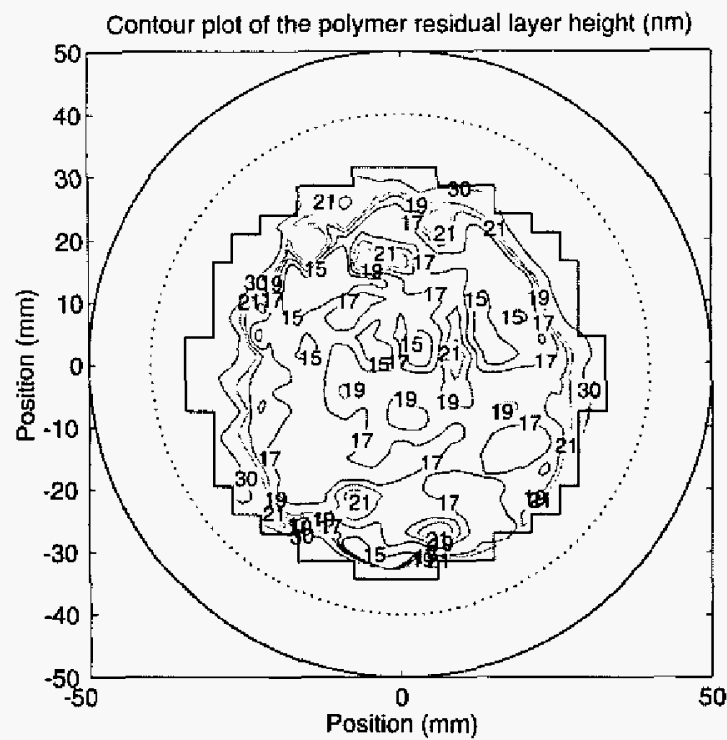

Figure 6: Measured polymer residual layer thickness $h_{r}$. Within a diameter of $50 \mathrm{~mm}$ the average residual layer thickness is found to $18.8 \mathrm{~nm}$ with a standard deviation of $6.6 \mathrm{~nm}$.

viation of $4.9 \mathrm{~nm}$. The stamp is imprinted into the PMMA by a homebuilt pressing tool. The imprint is performed in an evacuated environment having a pressure of $0.1 \mathrm{mbar}$, at a temperature of $170^{\circ} \mathrm{C}$ applying a force of $2000 \mathrm{~N}$ to the back side of the PDMS mattress. The imprint force is kept constant for $5 \mathrm{~min}$ before cooling is initiated. At a temperature of $70^{\circ} \mathrm{C}$ the imprint force is released and the stamp and substrate are manually separated.

Profilometer inspections show that the average imprint depth into the PMMA film is $249.4 \mathrm{~nm}$ with a standard deviation of $4.8 \mathrm{~nm}$ within the $50 \mathrm{~mm}$ diameter area, hence the stamp has not been completely filled during the imprint. Thereby the polymer residual layer thickness is determined by the parallelism between the stamp and substrate and the flow behavior of the polymer. The imprint is characterized with respect to the polymer residual layer thickness, $h_{r}$, which is easily measured with a small spot size spectro-reflectometer (NanoSpec). Within a diameter of $50 \mathrm{~mm}$ the average polymer residual layer thickness is found to $18.8 \mathrm{~nm}$ with a standard deviation of $6.6 \mathrm{~nm}$, see Fig. 6 . Both the absolute residual layer thickness and the variation is on the same length scale as the radius of gyration, $R_{g}$, which is $6.0 \mathrm{~nm}$ for $50 \mathrm{k}$ PMMA [6]. The radius of gyration is the characteristic length scale in a polymer network and for films in the order of a few $R_{g}$ the polymer can no longer be considered fluid, but rather like a rigid material due to the entanglements of the polymer chains.

\section{Conclusions}

A flexible silicon stamp for thermal NIL is presented and the performance with respect to polymer residual layer thickness is characterized. The design of the flexible stamp is based on MEMS technology, whereby the demands to the parallelism between the stamp and substrate in the imprint situation are decoupled from the NIL pressing tools. The flexible stamp is designed to imprint homogeneously in a parallel manner over large areas, and it inherently imprints the imprint areas parallel to the substrate. A highly uniform polymer residual layer is obtained over a $50 \mathrm{~mm}$ diameter large area. The imprint is characterized with respect to the polymer residual layer thickness. The polymer residual layer thickness is found to 18.8 $\mathrm{nm}$ within the $50 \mathrm{~mm}$ diameter with a standard deviation of $6.6 \mathrm{~nm}$. The polymer residual layer thickness is on the same length scale as the radius of gyration of the 50k PMMA. To our knowledge these results are state of the art within thermal NIL and comparable to the homogeneity results reported from UV-NIL [7, 8]. There are no identified obstacles in the fabrication of the flexible stamp that prevents it from being fabricated over larger areas.

\section{ACKNOWLEDGEMENTS}

The partial support of the EC-funded project $\mathrm{NaPa}$ (Contract no. NMP4-CT-2003-500120) is gratefully acknowledged. The contents of this work is the sole responsibility of the authors. One of the authors (R. H. Pedersen) gratefully acknowledges the financial support from the Oticon foundation.

\section{REFERENCES}

[1] S. Y. Chou, P. R. Krauss, and P. J. Renstrom, Appl. Phys. Lett. 67, 3114 (1995).

[2] H. Schulz, D. Lyebyedyev, H.-C. Scheer, K. Pfeiffer, G. Bleidiessel, G. Grützner, and J. Ahopelto, J. Vac. Sci. Technol, B 18, 3582 (2000).

[3] http://public.itrs.net/

[4] A. M. Hynes, H. Ashraf, J. K. Bhardwaj, J. Hopkins, I. Johnston, and J. N. Shepherd, Sensors and Actuators A 74, 13 (1999).

[5] A. A. Ayón, D.-Z. Chen, R. Khanna, R. Braff, H. H. Sawin, and M. A. Schmidt, Mat. Res. Coc. Symp. Proc. 605, 141 (2002).

[6] L. J. Fetters, D. J. Lohse, D. Rechter, T. A. Witten, and A. Zitkel, Macromolecules 27, 4639 (1994).

[7] U. Plachetka, M. Bender, A. Fuchs, B. Vratzov, T. Glinsner, F. Lindner, and H. Kurz, Microelectronic Engineering 73-74, 167 (2004).

[8] I. McMackin, J. Choi, P. Schumaker, V. Nguyen, F. $\mathrm{Xu}$, E. Thompson, D. Babbs, S. V. Sreenivasan, M. Watts, and N. Schumaker, Proceedings of SPIE 5374, 222 (2004). 